\title{
Metabolic Reprogramming in Mitochondria of Myeloid Cells
}

\author{
Hao Zuo ${ }^{1}\left(\mathbb{D}\right.$ and Yihong Wan ${ }^{1,2,3, *}$ \\ 1 Department of Pharmacology, The University of Texas Southwestern Medical Center, Dallas, TX 75390, USA \\ 2 Harold C. Simmons Comprehensive Cancer Center, The University of Texas Southwestern Medical Center, \\ Dallas, TX 75390, USA \\ 3 Hamon Center for Regenerative Science and Medicine, The University of Texas Southwestern Medical \\ Center, Dallas, TX 75390, USA \\ * Correspondence: Yihong.Wan@UTSouthwestern.edu; Tel.: +1-214-645-6062
}

Received: 19 November 2019; Accepted: 16 December 2019; Published: 18 December 2019

check for updates

\begin{abstract}
The myeloid lineage consists of multiple immune cell types, such as macrophages, monocytes, and dendritic cells. It actively participates in both innate and adaptive immunity. In response to pro- or anti-inflammatory signals, these cells undergo distinct programmed metabolic changes especially in mitochondria. Pro-inflammatory signals induce not only a simple shift from oxidative phosphorylation to glycolysis, but also complicated metabolic alterations during the early and tolerant stages in myeloid cells. In mitochondria, a broken Krebs cycle leads to the accumulation of two metabolites, citrate and succinate, both of which trigger pro-inflammatory responses of myeloid cells. A deficient electron transport chain induces pro-inflammatory responses in the resting myeloid cells while it suppresses these responses in the polarized cells during inflammation. The metabolic reprogramming in mitochondria is also associated with altered mitochondrial morphology. On the other hand, intact oxidative phosphorylation is required for the anti-inflammatory functions of myeloid cells. Fatty acid synthesis is essential for the pro-inflammatory effect and glutamine metabolism in mitochondria exhibits the anti-inflammatory effect. A few aspects of metabolic reprogramming remain uncertain, for example, glycolysis and fatty acid oxidation in anti-inflammation. Overall, metabolic reprogramming is an important element of immune responses in myeloid cells.
\end{abstract}

Keywords: metabolism; mitochondria; myeloid cells; macrophages; glycolysis; oxidative phosphorylation; Krebs cycle; electron transport chain; inflammation

\section{Introduction}

Metabolic reprogramming is an essential response for cells to various environmental and cellular stresses. Immune cells have common metabolism pathways as other cell types and they also have their unique metabolic changes in innate and adaptive immune responses. The history of studying the metabolism in immune cells (termed as immunometabolism) is longer than half a century, yet not until just a decade ago did researchers start to zoom in to the metabolic reprogramming during the differentiation and activation of immune cells [1-3]. Now, accumulating evidence demonstrates metabolic reprogramming as a key driver of immune responses of all immune cell types including macrophages, dendritic cells (DCs), and T cells [3,4].

The myeloid lineage is differentiated from the common myeloid progenitor, which is derived from hematopoietic stem cells in the bone marrow. The myeloid lineage includes macrophages, monocytes, neutrophils, eosinophils, basophils, erythrocytes, megakaryocytes, mast cells, and a subclass of DCs [5]. All these cells are widely distributed in all tissues through circulation and actively participate in various biological activities such as inflammation and wound repair. The myeloid cell lineage plays critical 
roles in both innate and adaptive immunity, and thus, together with the lymphoid lineage (natural killer cells, B cells, and T cells), constitutes a complete immune network in mammals.

Mitochondria are the central energy producers in cells due to their ability of generating numerous ATP from metabolizing fatty acids and the glycolytic product pyruvate through the Krebs cycle (also called TCA cycle) and the oxidative phosphorylation (OXPHOS). Another important role of mitochondria in the myeloid cells is producing reactive oxygen species (ROS) and metabolites to induce pro-inflammatory response and clear infection $[3,6]$. Mitochondria are also dynamic organelles constantly undergoing fusion and fission to maintain normal functions of mitochondria and regulate metabolism [7].

Some myeloid cells are divided into pro-inflammatory subtypes and anti-inflammatory subtypes, such as M1 and M2 macrophages, and N1 and N2 neutrophils [8]. In vitro, M1 macrophages are differentiated in the presence of IFN $\gamma$ and Toll-like receptor (TLR) ligands, such as lipopolysaccharide (LPS), while M2 macrophages are induced by IL-4. These two subtypes have distinct metabolism remodeling phenotypes [3]. M1 macrophage polarization is believed to induce a metabolic shift from OXPHOS to aerobic glycolysis (also called Warburg effect), while M2 macrophage polarization relies on OXPHOS [3]. However, recent studies provide new concepts and more details for these phenotypes. In this review, we summarize recent findings and reveal a complex network of metabolic reprogramming in the mitochondria of myeloid cells.

\section{Glycolysis and Oxidative Phosphorylation}

The common opinion of the metabolism reprograming during the activation of myeloid cells by pro-inflammatory signals, such as LPS, includes a glycolytic burst and a suppressed OXPHOS [3]. To achieve these phenotypes, LPS activates two metabolic regulators, the mammalian target of rapamycin (mTOR) and Hypoxia-inducible factor- $1 \alpha$ (HIF1 $\alpha$ ) [9], and suppresses AMP-activated protein kinase (AMPK) [10]. However, recent findings have demonstrated more complicated changes of these two events after LPS-induced activation (Table 1). Based on recent findings, the effect of LPS on glycolysis and OXPHOS can be divided into three periods: early response, sustained response, and tolerant response.

Table 1. The effect of LPS on glycolysis and OXPHOS.

\begin{tabular}{|c|c|c|c|c|c|c|c|}
\hline LPS (ng/mL) & $\begin{array}{c}\text { Treatment } \\
\text { Period (hour) }\end{array}$ & Cell Type & Glycolysis & OXPHOS & \begin{tabular}{l}
\multicolumn{1}{c}{ Pro- } \\
Inflammatory \\
Cytokines
\end{tabular} & Year & Reference \\
\hline \multicolumn{8}{|l|}{ Early response } \\
\hline 100 & $0-2$ & BMDMs & $\uparrow$ & $\downarrow$ & $\uparrow$ & \multirow{2}{*}{2012} & \multirow{2}{*}{ [11] } \\
\hline 100 & $0-4$ & RAW 264.7 & $\uparrow$ & $\downarrow$ & & & \\
\hline 100 & 4 & BMDMs & $\uparrow$ & $\uparrow$ & $\uparrow$ & 2013 & [12] \\
\hline 100 & 1 & BMDMs & & $\uparrow \uparrow$ & & 2019 & [13] \\
\hline 100 & $0.5,1$ & BMDMs & & $\uparrow$ & & 2019 & [14] \\
\hline 100 & $0-2$ & BMDMs & $\uparrow$ & n.c. & & \multirow{2}{*}{2016} & \multirow{2}{*}{ [15] } \\
\hline 100 & $0-2$ & hMDMs & $\uparrow$ & n.c. & & & \\
\hline 100 & $0-2$ & BMDMs & $\uparrow$ & n.c. & & 2018 & [16] \\
\hline 100 & $0-4$ & Peritoneal $\mathrm{m} \Phi$ & $\uparrow$ & & & 2010 & [17] \\
\hline 10 & 4 & Monocytes & $\uparrow$ & $\uparrow$ & & 2016 & [18] \\
\hline 100 & $0-1$ & Monocytes & $\uparrow$ & $\uparrow$ & & 2017 & [19] \\
\hline 100 & $0-6$ & BMDCs & & $\uparrow$ & & 2012 & [20] \\
\hline 100 & $0-2$ & BMDCs & $\uparrow$ & n.c. & & 2014 & [21] \\
\hline \multicolumn{8}{|c|}{ Sustained response } \\
\hline 100 & $8,16,24$ & BMDMs & $\uparrow$ & $\downarrow$ & $\uparrow$ & 2013 & [12] \\
\hline
\end{tabular}


Table 1. Cont.

\begin{tabular}{|c|c|c|c|c|c|c|c|}
\hline LPS (ng/mL) & $\begin{array}{c}\text { Treatment } \\
\text { Period (hour) }\end{array}$ & Cell Type & Glycolysis & OXPHOS & $\begin{array}{l}\quad \text { Pro- } \\
\text { Inflammatory } \\
\text { Cytokines }\end{array}$ & Year & Reference \\
\hline 100 & 24 & BMDMs & $\uparrow$ & $\downarrow$ & $\uparrow$ & 2015 & [22] \\
\hline 100 & 24 & BMDMs & $\uparrow$ & $\downarrow$ & & 2016 & [23] \\
\hline 100 & 24 or 48 & BMDMs & $\begin{array}{c}\uparrow \\
\imath\end{array}$ & $\downarrow$ & $\uparrow$ & 2016 & [24] \\
\hline 100 & 24 & BMDMs & $\uparrow$ & $\downarrow$ & & 2016 & [15] \\
\hline 10 & 12 & BMDMs & n.c. & $\uparrow$ & & \multirow{3}{*}{2016} & \multirow{3}{*}{ [25] } \\
\hline 100 & 12 & BMDMs & $\uparrow$ & $\downarrow$ & & & \\
\hline 5000 & 12 & BMDMs & $\uparrow$ & $\downarrow$ & & & \\
\hline 100 & 24 & BMDMs & $\uparrow$ & $\downarrow$ & $\uparrow$ & 2017 & [26] \\
\hline 100 & $4-24$ & BMDMs & & $\downarrow$ & $\uparrow$ & 2019 & [13] \\
\hline 1000 & 16 & mBMDMs & $\uparrow$ & $\downarrow$ & $\uparrow$ & \multirow{2}{*}{2019} & \multirow{2}{*}{ [27] } \\
\hline 1000 & 16 & hMDMs & $\downarrow$ & n.c. & $\uparrow$ & & \\
\hline 100 & $4-12$ & Peritoneal $\mathrm{m} \Phi$ & $\uparrow$ & & $\uparrow$ & 2010 & [17] \\
\hline 10 & 24 & Monocytes & $\uparrow$ & & $\uparrow$ & 2014 & [28] \\
\hline $1-100$ & 24 & Monocytes & $\uparrow$ & $\downarrow$ & $\uparrow$ & \multirow{2}{*}{2016} & \multirow{2}{*}{ [18] } \\
\hline 0.1 & 24 & Monocytes & $\uparrow$ & $\bar{\uparrow}$ & $\uparrow$ & & \\
\hline 10 & 4 or 24 & PBMCs & $\uparrow$ & $\downarrow$ & $\uparrow$ & 2016 & [29] \\
\hline 10 & 18 & RAW 264.7 & $\uparrow$ & $\downarrow$ & & 2017 & [30] \\
\hline 100 & 24 & Neutrophils & $\uparrow$ & $\downarrow$ & & 2019 & [31] \\
\hline 100 & 24 & BMDCs & $\uparrow$ & $\downarrow$ & & 2010 & [32] \\
\hline 100 & $6-24$ & BMDCs & $\uparrow$ & $\downarrow$ & $\uparrow$ & 2012 & [20] \\
\hline 100 & 24 & BMDCs & $\uparrow$ & $\downarrow$ & & 2014 & [33] \\
\hline 1000 & 24 & BMDCs & $\uparrow$ & $\downarrow$ & & 2019 & [34] \\
\hline 50 & 6 or 24 & Microglia & $\uparrow$ & $\uparrow$ & & \multirow{3}{*}{2019} & \multirow{3}{*}{ [35] } \\
\hline 100 & 6 & Microglia & $\uparrow$ & $\uparrow$ & & & \\
\hline 100 & 24 & Microglia & $\uparrow$ & $\downarrow$ & $\uparrow$ & & \\
\hline
\end{tabular}

\begin{tabular}{|c|c|c|c|c|c|c|c|}
\hline \multicolumn{8}{|c|}{ Tolerant response } \\
\hline $\begin{array}{l}\text { First LPS } \\
\text { (ng/mL) for } \\
\text { period (hour) }\end{array}$ & $\begin{array}{l}\text { Second LPS } \\
\text { (ng/mL) for } \\
\text { period (hour) }\end{array}$ & & & & & & \\
\hline 100 for 24 & 10 for 4 & BMDMs & & $\downarrow^{*}$ & $\downarrow *$ & 2019 & [13] \\
\hline 100 for 24 & 10 for 24 & hMDMs & & & $\downarrow^{*}$ & 2014 & [36] \\
\hline 10 for 24 & 10 for 24 & Monocytes & $\downarrow^{*}$ & $\downarrow *$ & & 2016 & [29] \\
\hline
\end{tabular}

\subsection{Early Response}

As shown in Table 1, glycolysis is enhanced in the early response period $(0-4 \mathrm{~h})$ in macrophages, monocytes and DCs, but the changes of OXPHOS are not consistent among different studies. Real-time changes of glycolysis can be measured by lactate release and extracellular acidification rate (ECAR), and OXPHOS is measured by oxygen consumption rate (OCR).

During the early response, one report demonstrates that LPS reduces real-time OCR in macrophages [11]. However, some other real-time measurements of OCR in murine bone marrow-derived macrophages (BMDMs), human monocyte-derived macrophages (hMDMs) and DCs show that LPS causes neither increase nor reduction of OXPHOS during the first $2 \mathrm{~h}[15,16,21]$. Moreover, LPS is also reported to cause a transient increase of OXPHOS within 1 or $6 \mathrm{~h}[19,20]$. 
In addition, measurements of OCR at $0.5,1$, or $4 \mathrm{~h}$ after LPS treatment indicate elevated OXPHOS at these time points [12-14,18]. Whether LPS stimulation leads to a transient increase and/or delayed decrease of OXPHOS in the myeloid cells needs more evidence.

The molecular mechanism of the glycolysis burst in the early response involves TBK1-IKK $\varepsilon$ and Akt-dependent activation of the glycolytic enzyme hexokinase [21]. Mechanisms of the possible transient increase of OXPHOS by LPS are investigated as well. LPS-induced OXPHOS depends on glucose oxidation, which also supports the availability of acetyl-CoA for histone acetylation at the promoters of pro-inflammatory cytokines within $2 \mathrm{~h} \mathrm{[13],} \mathrm{although} \mathrm{acetyl-CoA} \mathrm{is} \mathrm{also} \mathrm{reported} \mathrm{to} \mathrm{be}$ reduced by LPS [11]. By global metabolite profiling, Glycerol 3-phosphate shuttle (GPS) pathway is identified as the top-upregulated pathway by LPS [13]. This pathway can shuttle electrons from cytosolic glycolytic NADH to $\mathrm{FADH}_{2}$ for fueling the mitochondrial electron transport chain (ETC). LPS increases the activity of the GPS enzyme mitochondrial glycerol 3-phosphate dehydrogenase (GDP2) to drive mitochondrial respiration [13]. GDP2 knockout (KO) blocks the increase of OCR by LPS in BMDMs [13]. In addition, mitochondrial Complex III (CIII) inhibitor suppresses ROS production in the first hour of IFN $\gamma /$ LPS treatment [14]. Revisable transient inhibition of CIII for the first one hour is sufficient to block the pro-inflammatory cytokine production during the entire 18-h treatment of IFN $\gamma /$ LPS [14]. Therefore, normal CIII activity in the early response is required for myeloid cell activation.

\subsection{Sustained Response}

LPS treatment (1-100 $\mathrm{ng} / \mathrm{mL}$ ) for 4-24 h results in increased glycolysis and decreased OXPHOS (Table 1). Transcriptome analysis shows that LPS treatment up-regulates the expression of glycolytic genes and down-regulates the expression of OXPHOS genes $[12,17,18,23]$. The metabolite profile of LPS-induced myeloid cells reveals accumulated glycolytic intermediates and intermediates of the Krebs cycle, including citrate and succinate $[12,15,18]$. LPS induced glycolysis is mediated by the PI3K/Akt pathway and HIF1 $\alpha$ stabilization, and antagonized by AMPK [12,32]. LPS treatment also triggers the nuclear translocation of the glycolytic enzyme PKM2 to form a complex with HIF1 $\alpha$ and regulate glycolysis and pro-inflammatory cytokine production [22]. LPS increases mTOR-mediated inducible nitric oxide synthase (iNOS), and subsequent nitric oxide (NO) production inhibits OXPHOS [20,33].

The metabolic alterations in different conditions (dose, ligand and cell type) may be very complicated. Treatment of $0.1 \mathrm{ng} / \mathrm{mL}$ LPS for $24 \mathrm{~h}$ in monocytes induces an elevation of both glycolysis and OXPHOS [18]. Treatment of $10 \mathrm{ng} / \mathrm{mL}$ LPS for $12 \mathrm{~h}$ also induces a slight increase of OXPHOS without modulating glycolysis [25]. LPS is the antigen from Gram-negative bacteria (e.g., E. coli) and activates TLR4 receptors of immune cells. Treatment of $\mathrm{Pam}_{3} \mathrm{CysSK}_{4}$ (P3C, TLR2 ligand), poly(I:C) (TLR3 ligand) or lysates from E. coli, S. aureus and M. tuberculosis lead to both increased glycolysis (measured by ECAR and lactate production) and increased or unchanged OXPHOS (measured by OCR, SRC and the activity of several enzymes in the ETC) [18]. However, in another report, treatment of P3C, poly(I:C), R848 (TLR7/8 ligand), and CpG (TLR9 ligand) decreased OCR in DCs [20]. The metabolic changes in human and murine macrophages may be quite different, because LPS-stimulated mouse BMDMs had increased glycolysis and decreased OXPHOS as most other reports, but LPS stimulated hMDMs had a slightly decreased glycolysis and unaltered OXPHOS [27]. Microglia functions as resident macrophages in the central nerves system. Similar Warburg effect was observed in microglia after $100 \mathrm{ng} / \mathrm{mL}$ LPS treatment for $24 \mathrm{~h}$, but $100 \mathrm{ng} / \mathrm{mL}$ LPS treatment for $6 \mathrm{~h}$ or $50 \mathrm{ng} / \mathrm{mL}$ LPS treatment for 6 or $24 \mathrm{~h}$ increased both glycolysis and OXPHOS [35]. Although the metabolic reprogramming in the myeloid cells has been studied extensively, further investigations on the antigen diversity, the dosage dependent effect and immune cell type dependent responses are necessary.

\subsection{Tolerant Response}

A low dose of LPS pretreatment induces a tolerant state of monocytes and macrophages which are unable to respond to further LPS challenge. The tolerance leads to suppressed immune response 
upon the subsequent stimulation by the lethal dose of LPS, thus prevents cytokine storm, tissue damage and mortality from septic shock [37]. In vitro, tolerant monocytes and macrophages have reduced gene expression related to glycolysis, OXPHOS, and cytokine production after a second LPS stimulation in comparison to stimulated non-tolerant cells $[13,29,36]$. The altered metabolism in tolerant myeloid cells is due to an impaired mTOR pathway [29] and GDP2-mediated reverse electron transport (RET), which is the consequence of overwhelming the electron transport chain (ETC) [13]. There is a negative feedback regulation that LPS induces the expression of anti-inflammatory IL-10 and IL-10 in turn inhibits glycolysis and preserves OXPHOS by down-regulating NO production, mTOR activity, glycolytic enzyme expression and preventing the accumulation of dysfunctional mitochondria $[15,26]$.

\subsection{Glycolysis and OXPHOS in M2 Macrophages}

IL-4 has very little effect on glycolysis and no effect on OXPHOS in BMDMs [11,16]. Intact OXPHOS is required for M2 polarization [16,38]. IL-4 induces Akt-dependent increased glycolysis and $\mathrm{Akt} / \mathrm{mTORC} 1 / \mathrm{ATP}$-citrate lyase (ACLY) mediated histone acetylation of M2 genes [39]. In addition, IL-4 enhances glucose uptake, glycolysis rate, and glycolytic enzyme expression through STAT6 and PI3K/Akt/mTORC2 mediated IRF4 expression [40]. Glycolysis inhibition by the glucose analogue 2-deoxyglucose (2-DG) suppresses glycolysis, OXPHOS and IL-4 induced M2 polarization [40]. However, 2-DG affects not only glycolysis but also OXPHOS. The inhibition of M2 polarization by 2-DG depends on reduced ATP production followed by impaired STAT6 activation [16]. On the other hand, different glucose concentrations in medium do not affect STAT6 phosphorylation, ATP production, OXPHOS, and M2 polarization [16]. The changes of glycolysis may be compensated for by increased glutamine fueling of Krebs cycle induced by IL-4 [16]. Thus, it is still not clear whether glycolytic reprogramming is required or not for M2 polarization.

\section{Mitochondrial Fragmentation and Mitophagy}

LPS stimulation induces changes of the mitochondrial morphology. The length of mitochondria is much smaller after $2 \mathrm{~h}$ of LPS treatment, indicating LPS-induced mitochondrial fragmentation in microglia and macrophages [35,41-44]. Treatment of Mdivi-1, an inhibitor of mitochondrial fission and fragmentation by targeting dynamin-related protein 1 (Drp1) [45], restores the mitochondrial morphology and attenuates LPS-induced responses, including increased membrane potential, succinate accumulation, the shift of OXPHOS to glycolysis, and the production of ROS and cytokines $[35,41,44]$. In addition to Mdivi-1 mediated blockage of LPS-stimulated ROS production, ROS seems to participate in LPS-induced mitochondrial fragmentation as the treatment of the ROS scavenger $\mathrm{N}$-acetyl cysteine (NAC) restores LPS-induced mitochondrial fragmentation [42]. The capability of macrophages for clearing up apoptotic cells relies on apoptotic cell-induced mitochondrial fragmentation via Drp1 and is diminished by Mdivi-1 [46]. It should be noted that Mdivi-1 is also reported to have off-target effect including suppressing ROS production by Complex I in non-myeloid cells [47].

Cells utilize mitophagy to clear dysfunctional mitochondria. The smaller size of mitochondria may not trigger damaged mitochondria-induced mitophagy [48]. Nevertheless, mitophagy plays essential roles in IFN $\gamma /$ LPS-induced macrophage polarization. The mitophagy/autophagy inhibitor 3-methyladenine (3-MA) impairs the expression of glycolytic enzymes, increases mitochondrial mass and reduces pro-inflammatory cytokines induced by IFN $\gamma /$ LPS [43]. In LPS-primed macrophages, ETC inhibitors (rotenone/antimycin A) cause mitochondria damages followed by mitophagy, resulting in more ROS production [49,50]. In unstimulated macrophages, the treatment of 3-MA induces accumulation of damaged mitochondria and activation of NLRP3 inflammasome as well as increases ROS generation and IL-1 $\beta$ secretion [49], indicating that mitophagy may clear ROS-producing damaged mitochondria to prevent excessive ROS production and inflammation. 


\section{Krebs Cycle}

The Krebs cycle (TCA cycle) is an essential process in transforming fuel molecules to energy. It consists of multiple steps converting intermediates: citrate, iso-citrate, $\alpha$-ketoglutarate $(\alpha K G)$, succinate, fumarate, malate, and oxaloacetate. It generates $\mathrm{NADH}$ and $\mathrm{FADH}_{2}$ to provide electron for OXPHOS.

During IFN $\gamma /$ LPS-induced macrophage polarization, two breakpoints of Krebs cycle are induced by IFN $\gamma /$ LPS [51]. One breakpoint of Krebs cycle is downregulated isocitrate dehydrogenase (IDH), resulting an accumulation of isocitrate and a reduction of $\alpha \mathrm{KG}$ [51]. Accumulated citrate is exported from mitochondria into cytosol by the mitochondrial citrate carrier (CIC), which is also up-regulated by LPS stimulation [52]. Then, cytosolic citrate can be converted back to oxaloacetate and acetyl-CoA by ACLY and these acetyl-CoA are utilized in histone acetylation to facilitate inflammatory cytokine expression $[13,53]$. Meanwhile, IFN $\gamma /$ LPS increases the conversion of citrate to itaconate $[51,54]$ by up-regulating the enzyme expression (encoded by $\operatorname{Irg} 1$ gene) $[51,55,56]$. Itaconate is an anti-inflamatory metabolite that inhibits succinate dehydrogenase (SDH)-mediated succinate oxidation $[56,57]$ and activates anti-inflammatory transcription factors Nrf2 and ATF3 [58,59]. These findings indicate a negative feedback regulation after the activation of myeloid cells. The induction of itaconate followed by SDH inhibition also modulate the tolerance of myeloid cells and $\beta$-glucan can counteract the tolerance by inhibiting the expression of Irg1 [60].

Another breakpoint of Krebs cycle occurs at the succinate to fumarate transition [51], leading to the succinate accumulation after LPS stimulation [12,51]. Succinate increases HIF- $1 \alpha$ stability and HIF-1 $\alpha$-induced cytokine expression [12]. This accumulation of succinate may be from glutamine metabolism-dependent anerplerosis [61]. Considering that glutamine contributes one third of carbons for accumulated succinate during M1 polarization [51] and a minimum of glutamine $(0.03 \mathrm{mM})$ is required for LPS-induced macrophage activation [62], the fast conversion of glutamine- $\alpha$ KG-succinate may be an essential step to maintain pro-inflammatory responses in macrophages. This point is supported by the evidence that LPS induces higher $\alpha \mathrm{KG}$ dehydrogenase $(\alpha-\mathrm{KGDH})$ activity and the $\alpha \mathrm{KG} /$ succinate ratio negatively regulates LPS-induced macrophage activation [63]. Moreover, in LPS-induced tolerant macrophages, inhibition of glutamine metabolism to $\alpha \mathrm{KG}$ enhances the inflammatory effect of a second LPS stimulation, as well as abolishes LPS tolerance-induced protection from septic shock in mice [63], indicating an anti-inflammatory role of glutamine/ $\alpha \mathrm{KG}$ in macrophage tolerance.

\section{Electron Transport Chain}

ETC and ATP synthase (also called Complex V) forms the OXPHOS and produces the majority of ATP during aerobic respiration. It consists of four protein complexes (Complex I to IV) and two electron carriers (ubiquinone and cytochrome c). Complex I oxidizes NADH, transfers electrons to ubiquinone $(Q)$ and transport protons from the matrix to the intermembrane space, which results in a proton gradient. Complex II transfers electrons of $\mathrm{FADH}_{2}$ originated from succinate to $\mathrm{Q}$ without proton transport. Complex III transfers electrons from $\mathrm{Q}$ to cytochrome $\mathrm{c}$ and transports protons contributing the proton gradient. Complex IV transfers electrons from cytochrome $\mathrm{c}$ to the oxygen molecule $\left(\mathrm{O}_{2}\right)$ generating $\mathrm{H}_{2} \mathrm{O}$ and transports protons forming the proton gradient. At last, the proton gradient drives ATP production by ATP synthase.

\subsection{Mitochondrial Complex I}

One of major ROS production sites is through the electron leak at Complex I (CI) during the forward electron transport (FET) and the reverse electron transport (RET) [64]. A highly reduced pool of $Q$ and a large membrane potential (proton gradient) trigger the reverse electron transport (RET) from over-reduced Q back to CI [64,65]. During RET, Q is over-reduced by electrons from Complex II (CII) and other sources such as GPS shunt. The CI inhibitor rotenone blocks the electron transport 
between $\mathrm{CI}$ and Q. During FET, rotenone suppresses the electron transport to Q causing electron leak and increased ROS production in some cell types such as skin fibroblasts [66], while during RET, rotenone prevents the electron transport back from $Q$ leading to reduced ROS production in other cell types such as polarized macrophages $[67,68]$.

In resting myeloid cells, early studies show decreased ROS by rotenone, but a lot more recent evidence indicate the enhanced ROS and pro-inflammatory cytokine production by rotenone (Table 2), suggesting that increased ROS may be resulted from impaired FET in the resting cells. BMDMs have a reduced amount of $\mathrm{CI}$ and the decreased association of $\mathrm{CI}$ with other mitochondrial respiration complexes in response to bacteria [69], indicating that macrophage activation by infection is associated with lower FET and OXPHOS. In LPS-stimulated myeloid cells, especially after the prolonged treatment (8-24 h), the ROS production and pro-inflammatory cytokine production are reduced by rotenone (Table 2), which may be due to decreased CI mediated RET. Deficiency of the GPS enzyme GDP2 reduces rotenone-induced ROS decrease [13], suggesting that GPS-mediated Q reduction also contributes to RET after LPS stimulation.

Table 2. The effect of Complex I inhibitor rotenone on unstimulated or LPS-stimulated myeloid cells.

\begin{tabular}{|c|c|c|c|c|c|c|c|c|}
\hline $\begin{array}{l}\text { Rotenone } \\
(\mu \mathrm{M})\end{array}$ & $\begin{array}{l}\text { Rotenone } \\
\text { Treatment }\end{array}$ & $\begin{array}{c}\text { LPS }(\mu \mathrm{g} / \mathrm{mL}) \\
\text { for Period }\end{array}$ & Cell Type & $\begin{array}{c}\text { ROS } \\
\text { Method }\end{array}$ & mROS & \begin{tabular}{l}
\multicolumn{1}{c}{ Pro- } \\
Inflammatory \\
Cytokines
\end{tabular} & Year & Reference \\
\hline \multicolumn{9}{|c|}{ Single Agent } \\
\hline 2 & $\overline{0}-30 \mathrm{~min}$ & & Alveolar $m \Phi$ & LDCL & $\downarrow$ & & 1994 & [70] \\
\hline $0.1-10$ & $0-30 \mathrm{~min}$ & & ML1-M & LDCL & $\downarrow$ & & 1998 & [68] \\
\hline $0.2-5$ & $30 \mathrm{~min}$ & & HL-60 & PHPA & $\uparrow$ & & 2003 & [71] \\
\hline 10 & $90 \mathrm{~min}$ & & BMDMs & $\mathrm{DCFH}_{2}$-DA & $\uparrow$ & & 2008 & [72] \\
\hline 10 & $6 \mathrm{~h}$ & & THP-1 & MitoSOX & 个 & $\uparrow$ & 2011 & [49] \\
\hline 5 & $30 \mathrm{~min}$ & & J774A.1 & MitoSOX & $\uparrow$ & & 2011 & {$[73]$} \\
\hline 0.5 & $16 \mathrm{~h}$ & & RAW 264.7 & MitoSOX & $\uparrow$ & & 2011 & [74] \\
\hline 0.01 & $30 \mathrm{~min}$ & & $\begin{array}{l}\text { Peritoneal } \\
\mathrm{m} \Phi\end{array}$ & WST-1 & $\uparrow$ & & 2012 & \multirow{2}{*}{ [75] } \\
\hline 0.01 & $30 \mathrm{~min}$ & & Microglia & WST-1 & $\uparrow$ & & 2012 & \\
\hline $0.001-0.1$ & $6 \mathrm{~h}$ & & $\begin{array}{c}\text { BV2 } \\
\text { microglia }\end{array}$ & DCFH-DA & $\uparrow$ & $\uparrow$ & 2013 & [76] \\
\hline 1 & $6 \mathrm{~h}$ & & $\begin{array}{c}\text { BV2 } \\
\text { microglia }\end{array}$ & DCFH-DA & $\uparrow$ & $\uparrow$ & 2013 & [77] \\
\hline 0.01 & $18 \mathrm{~h}$ & & Microglia & DCFH-DA & $\uparrow$ & & 2014 & [78] \\
\hline 0.5 & $25 \mathrm{~h}$ & & BMDMs & CellROX & n.c. & & 2015 & [79] \\
\hline 5 & $2 \mathrm{~h}$ & & BMDMs & MitoSOX & $\uparrow$ & n.c. & 2015 & [80] \\
\hline 1 & $1.5 \mathrm{~h}$ & & BMDMs & MitoSOX & $\uparrow$ & & 2016 & [69] \\
\hline 10 & $0-30 \mathrm{~min}$ & & ML1-M & LDCL & $\downarrow$ & & 2016 & [81] \\
\hline unknown & & & $\begin{array}{c}\mathrm{m} \Phi \text { from } \\
\text { THP-1 }\end{array}$ & DCFH-DA & $\uparrow$ & & 2017 & [82] \\
\hline 2 & $30 \mathrm{~min}$ & & hMDMs & MitoSOX & $\uparrow$ & & 2019 & [27] \\
\hline 1.5 & $0-100 \mathrm{~s}$ & & BMDMs & MitoSOX & $\uparrow$ & & 2019 & [13] \\
\hline \multicolumn{9}{|c|}{ Co-treatment } \\
\hline 1 & $18 \mathrm{~h}$ & 1 for $18 \mathrm{~h}$ & J774.1 & DCFH-DA & $\downarrow$ & $\downarrow$ & 2000 & [83] \\
\hline 5 & $\begin{array}{l}10 \mathrm{~min}+ \\
30 \mathrm{~min}\end{array}$ & 0.1 for $30 \mathrm{~min}$ & RAW 264.7 & \multicolumn{2}{|c|}{ DCFH-DA/LDCL $\downarrow$} & & 2004 & [84] \\
\hline 0.5 & $1 \mathrm{~h}+24 \mathrm{~h}$ & 1 for $24 \mathrm{~h}$ & BMDMs & CellROX & $\downarrow$ & $\downarrow$ & 2015 & [79] \\
\hline 0.5 & $3 h+24 h$ & 1 for $24 \mathrm{~h}$ & BMDMs & CellROX & $\downarrow$ & $\downarrow$ & 2016 & {$[24]$} \\
\hline 0.1 & $1 \mathrm{~h}+8 \mathrm{~h}$ & 1 for $8 \mathrm{~h}$ & RAW 264.7 & $\mathrm{DCFH}_{2}-\mathrm{DA}$ & $\downarrow$ & $\downarrow$ & 2018 & [85] \\
\hline 1.5 & $0-100 \mathrm{~s}$ & 0.1 for $12 \mathrm{~h}$ & BMDMs & MitoSOX & $\downarrow$ & & 2019 & [13] \\
\hline
\end{tabular}

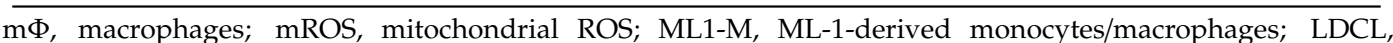
Lucigenin-derived chemiluminescence; s, second; min, minute, h, hour; n.c. no change; $\uparrow$ increased; $\downarrow$ decreased. 
Besides pharmaceutical inhibition, genetic models of $\mathrm{CI}$ are also utilized. $\mathrm{CI}$ is a supercomplex of 45 subunits which form three modules: $\mathrm{N}$ module (oxidizing NADH and electron input), Q module (electron output to ubiquinone) and P module (proton transport) [86]. Deficiency of CI accounts for about $30 \%$ of mitochondria disorders including Leigh syndrome and lactic acidosis [86]. Ndufs4 is a subunit of $\mathrm{N}$ module and its deletion in mice leads to a crippled $\mathrm{CI}$ without $\mathrm{N}$ module and decreased CI activity $[87,88]$, indicating defective electron input and FET for OXPHOS. Ndufs4 knockout (KO) mice die early at about week 7 , and Ndufs4 KO neonates show fur loss during week 2-4 [88-91]. Our group demonstrates that fur loss of global Ndufs4 $\mathrm{KO}$ mice is associated with a systematic inflammation including elevated pro-inflammatory cytokines in serum and expression of pro-inflammatory markers in cells from bone marrow, spleen, liver and skin together with the accumulation of monocytes/macrophages [91]. Ndufs4 KO BMDMs produce more lactate and ROS than wild-type (WT) BMDMs [91], indicating that CI deficiency leads to inflammatory responses and metabolic shift to glycolysis. CI deficiency induces $50 \%$ higher serum triglyceride and nonesterified fatty acid in Ndufs $4 \mathrm{KO}$ suckling neonates and this effect is due to defective fatty acid metabolism in liver [91]. Saturated fatty acids activate TLR2/4-mediated inflammation [92]. Indeed, Ndufs4+TLR2/4 triple KO rescues systemic inflammation in Ndufs4 KO mice [91], suggesting CI deficiency causes inflammation through both increased ROS in macrophages and defective fatty acid metabolism in the liver.

Another mouse model for studying CI is macrophage KO of ECSIT (evolutionarily conserved signaling intermediate in Toll pathways), a CI assembly protein $[93,94]$. ECSIT deletion leads to less CI, elevated glycolysis, impaired OXPHOS, reduced mitochondrial potential and increased ROS in unstimulated macrophages [94]. After TLR1/2/4 activation, TRAF6 mediates ECSIT ubiquitination and enrichment leading to ROS production, and ECSIT deletion in LPS-stimulated BMDMs results in reduced ROS and anti-bacteria response [74]. ECSIT forms a complex with TAK1 and TRAF6 in human monocyte THP-1 cells to enhance LPS-induced TLR4 signals [95]. Overall, the suppression of CI induces inflammation in unstimulated myeloid cells and impairs inflammation in stimulated myeloid cells.

\subsection{Complex II and III}

The activity of CII in myeloid cells is enhanced by inflammatory signals. LPS stimulation induces the oxidation of accumulated succinate by the increased activity of SDH (another name of CII) and increased mitochondrial membrane potential followed by mitochondrial ROS production and the cytokine expression [24]. Similarly, bacteria promote the activation of CII and the inflammatory responses in BMDMs [69].

CIII is another site of ROS generation in mitochondria. Myxothiazol (Myx) is a reversible CIII inhibitor that suppresses the electron transfer to $\mathrm{CIII}$ at the ubiquinol oxidation center $\mathrm{Q}_{\mathrm{o}}$ site, while antimycin A inhibits CIII by blocking $Q$ turn over at the ubiquinone-reduction center $Q_{i}$ site [96]. In unstimulated BMDMs and bone marrow neutrophils, antimycin A or Myx decreases membrane potential and increases ROS production $[72,96,97]$. In BMDMs stimulated by IFN $\gamma / \mathrm{LPS}$ for $1 \mathrm{~h}$, Myx blocks the IFN $\gamma /$ LPS-induced ROS production [14]. Interestingly, removal of the revisable inhibitor Myx after the first hour of LPS treatment is still able to diminish production of pro-inflammatory cytokines after LPS treatment for $18 \mathrm{~h}$ [14]. Moreover, Myx and antimycin A reduce NFkB nuclear accumulation after LPS treatment for $1 \mathrm{~h}$ and decrease the pro-inflammatory cytokine production after LPS treatment for $5 \mathrm{~h}$ in bone marrow neutrophils [97]. All these findings indicate a similar role of CIII as $\mathrm{CI}$ that suppressing $\mathrm{CIII}$ induces inflammatory responses in unstimulated myeloid cells and blocks inflammatory responses in LPS-stimulated myeloid cells, which may be associated with diminished FET and RET, respectively. 


\section{Fatty Acid Oxidation and Synthesis}

IFN $\gamma /$ LPS-induced M1 macrophages have increased fatty acid synthesis (FAS) [98-100]. FAS in M-CSF derived hMDMs is dramatically enhanced by the up-regulation of sterol regulatory element-binding transcription factor 1c (SREBP1c) target genes involved in FAS, such as fatty acid synthase [100]. Knocking down or inhibition of fatty acid synthase in LPS-stimulated BMDMs decreases the expression of pro-inflammatory cytokines [101]. Fatty acid synthase regulates cholesterol synthesis via the FAS intermediate metabolite acetoacetyl-CoA, which is also a metabolite in the cholesterol synthesis [101]. The cholesterol level regulated by FAS maintains the cholesterol-rich lipid rafts where TLR4 translocates in inflammation signaling [101].

Fatty acid oxidation (FAO) of M1 macrophages is decreased via suppressing the expression of CPT-1 [38,98], which transports fatty acid into mitochondria. Fatty acid is converted to acetyl-CoA, $\mathrm{NADH}$ and $\mathrm{FADH}_{2}$ by $\beta$-oxidation to fuel OXPHOS. Interestingly, glucose deprivation leads to reduced glycolysis and enhanced OXPHOS after LPS treatment as compared to normal glucose supplement [19]. The enhanced OXPHOS in the absence of glucose is due to $\beta$-oxidation of fatty acid, as inhibition of fatty acid transport into mitochondria by $250 \mu \mathrm{M}$ of the CPT-1 inhibitor etomoxir attenuates glucose deprivation-induced OXPHOS [19]. However, high doses of etomoxir $(>100 \mu \mathrm{M})$ have multiple off-target effects including inhibiting the adenine nucleotide translocase (ANT) and mitochondrial Complex I [102].

IL-4-induced M2 macrophages have increased FAO [38,103]. M2 macrophages and myeloid-derived suppressor cells (MDSCs) have increased OXPHOS which is suppressed by 100-200 $\mu \mathrm{M}$ of etomoxir $[16,103,104]$. However, another study shows that FAO may be dispensable for hMDMs, as IL-4 does not induce CPT-1 expression and $10 \mu \mathrm{M}$ etomoxir is sufficient to inhibit FAO, but not IL-4-induced polarization [105]. Conditional KO of CPT-2 in macrophages blocks FAO, but has no effect on M2 macrophage polarization [106]. Considering the possible off-target effects of etomoxir, FAO may participate but is dispensable in maintaining OXPHOS in IL-4-induced macrophage polarization

\section{Amino Acid Metabolism}

Glutamine deprivation does not affect IFN $\gamma /$ LPS-induced M1 polarization [51], but it dramatically suppresses IL-4-induced M2 polarization [51,63]. Glutamine provides one third of all carbons for metabolites in the Krebs cycle and supports the expression of chemokines in IL-4-induced M2 macrophages $[16,51,63]$. However, glutamine deprivation is also reported to elevate LPS-induced macrophage activation [63]. Glutamine can replenish Krebs cycle metabolite $\alpha \mathrm{KG}$, which is reduced during M1 polarization [51], via glutaminolysis. Inhibition of glutaminolysis enhances, while supplement of $\alpha \mathrm{KG}$ impairs, LPS-induced macrophage activation [63], suggesting glutamine and $\alpha \mathrm{KG}$ may have anti-inflammatory effect.

However, M. tuberculosis infection in human leads to an up-regulated expression of the glutaminolysis enzyme GLUD2 and increased $\alpha$ KG in macrophages [107]. Glutamine deprivation and inhibition of glutamine uptake or glutaminolysis decrease the $M$. tuberculosis-induced pro-inflammatory cytokine production in PBMCs [107].

Besides glutamine, aspartate is also involved in mitochondrial metabolic reprogramming during the activation of myeloid cells. The aspartate-argininosuccinate shunt (AASS) replenishes the malate pool of Krebs cycle, and inhibition of this shunt blocks the shift from OXPHOS to glycolysis and IFN $\gamma /$ LPS-induced M1 polarization [51].

\section{Concluding Remarks and Future Directions}

This review aims to summarize the current understandings of the critical roles of mitochondrial metabolic reprogramming for immune responses of myeloid cells. To perform their pro- or anti-inflammatory functions, myeloid cells adapt their metabolism by involving changes in almost every metabolic step (Figure 1). These cell-type specific metabolic changes then modulate immune 
responses of myeloid cells such as M1 and M2 macrophages (Figure 2). Most of the enzymes or metabolites have been extensively studied to exhibit a whole picture of metabolic reprogramming with a clear view of most parts and some fuzzy spots. These fuzzy spots need further investigation. Despite the exciting advancement of immunometabolism, there are still plenty of challenges waiting for immunologists. The dose, ligand and cell type-dependent effects request careful examinations to determine a more physiological relevant stimulation condition. The metabolic alterations in vitro may be quite different from those in vivo, but only limited in vivo models are available. Making the situation even more challenging, many enzyme inhibitors have off-target effects, for example, 2-DG, etomoxir and Mdivi-1 as discussed above. Genetic animal models should provide more specific effect. As genetic deficiency of metabolism affects development especially of the nerves system, it is better to use the conditional knockout by Cre expressed specifically in myeloid cells. Inducible gene expression or knockout is another option to establish in vivo models. Technology advancement will also benefit immunometabolism. For example, cryo-EM can reveal protein and organelle structures and single cell sequencing can demonstrate the diversity of immune responses. A better understanding of the complicated metabolic reprogramming process in immune cells will facilitate the discovery of new strategies to treat diseases related to immunity.

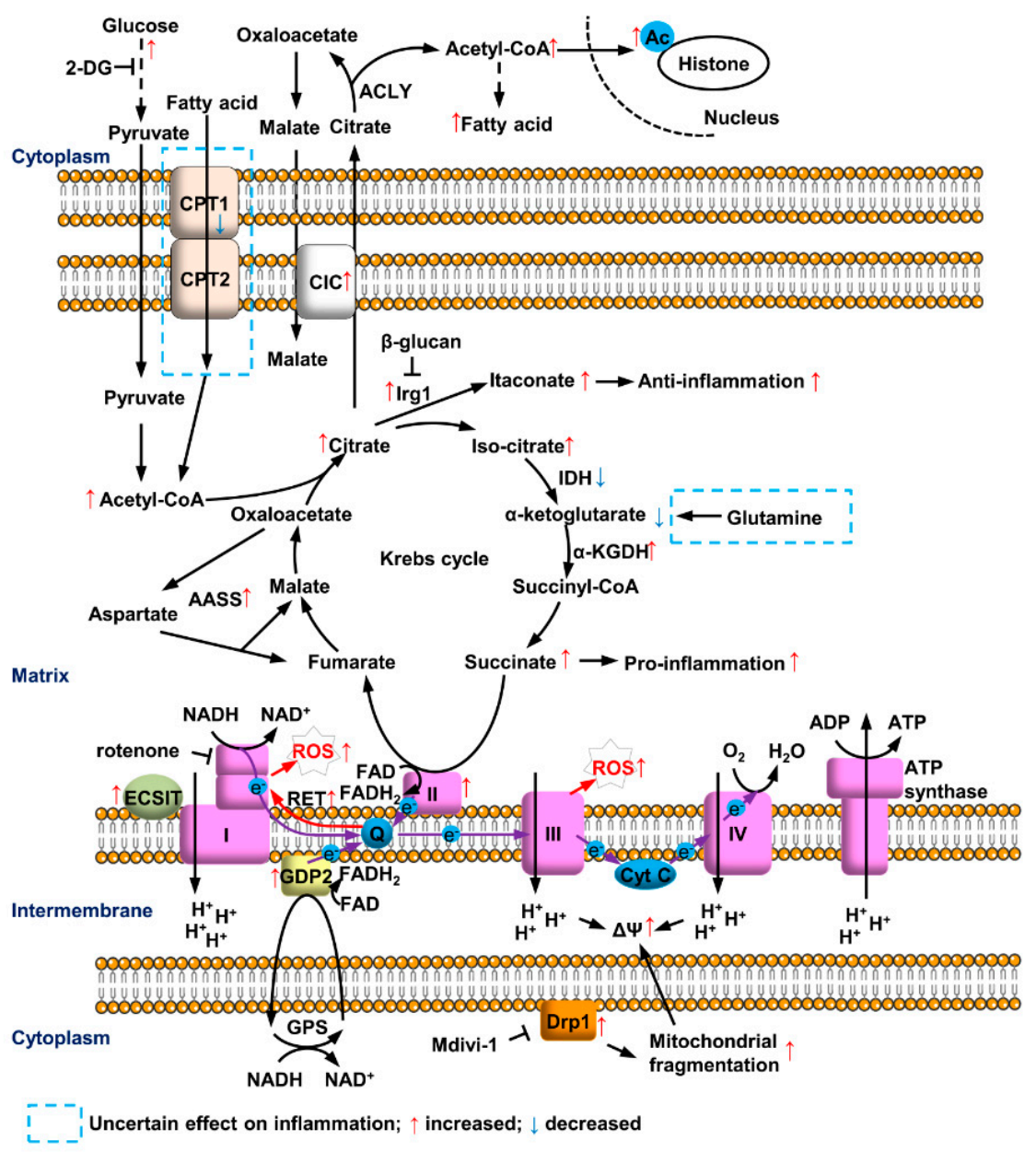

Figure 1. Mitochondrial metabolic reprogramming in myeloid cells after LPS treatment. LPS induces glycolysis and accumulation of citrate and succinate in Krebs cycle. Citrate triggers pro-inflammation by metabolizing to Acetyl-CoA and anti-inflammatory feedback regulation via converting to itaconate. Accelerated succinate oxidation at CII and GDP2-mediated GPS increase the reduction of ubiquinone (Q), leading to ROS production at CI and CIII of ETC. Fatty acid synthesis, AASS and mitochondrial fragmentation are involved, while the roles of fatty acid oxidation and glutamine metabolism are still not clear. 


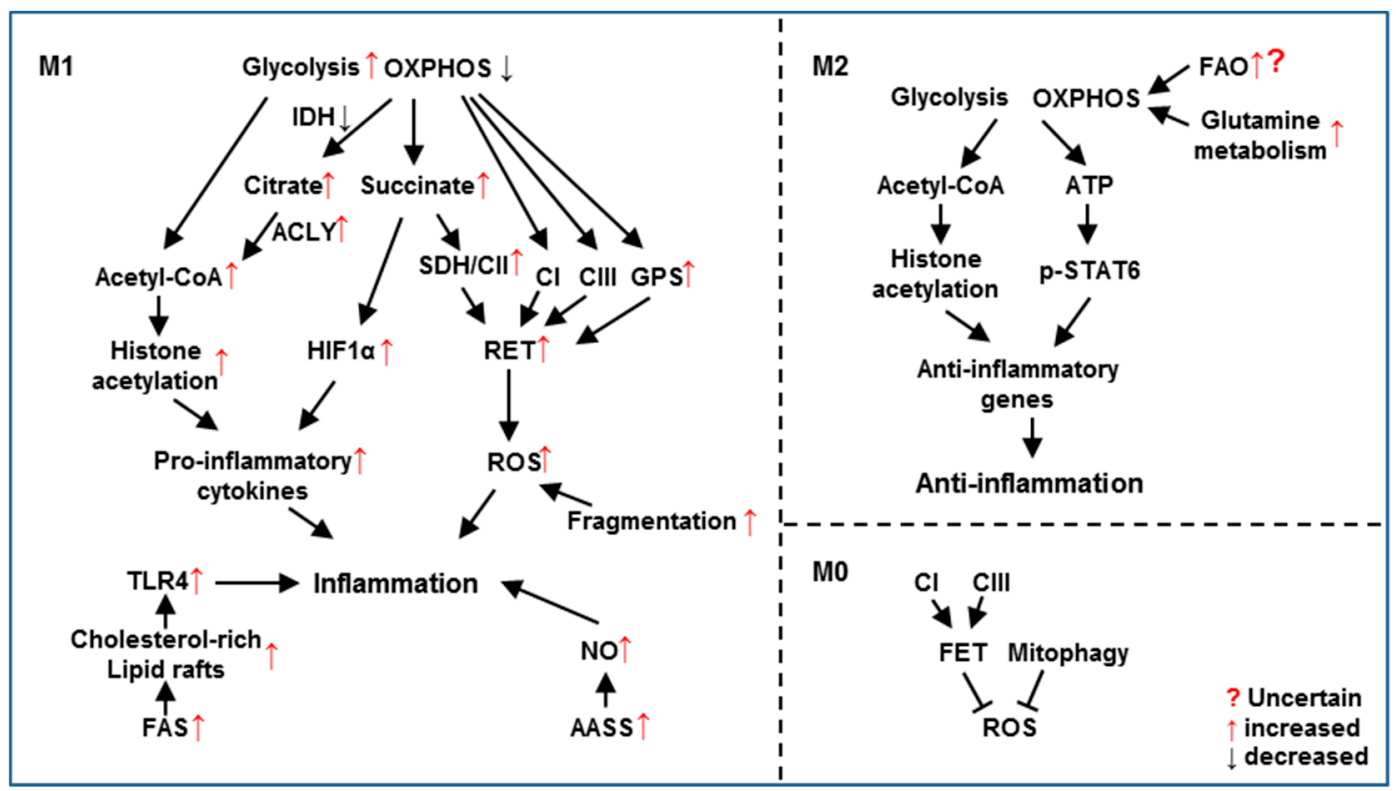

Figure 2. Mitochondrial metabolic reprogramming regulates functions of M1 and M2 macrophages. In M1 macrophages, increased glycolysis and decreased OXPHOS modulate the pro-inflammatory response through elevating histone acetylation, HIF1 $\alpha$ and RET. Increased FAS, AASS and mitochondrial fragmentation also contribute to M1 polarization. In M2 macrophages, intact glycolysis and OXPHOS are required for anti-inflammatory response by inducing histone acetylation and STAT6 phosphorylation. Glutamine metabolism is essential to replenish Krebs cycle while FAO's role is uncertain for M2 polarization. In M0/unstimulated macrophages, inhibition of CI or CIII blocks FET followed by ROS production. Mitophagy removes ROS-producing damaged mitochondria.

Funding: This work was supported by NIH/NCI (R01CA229487, R01CA236802, Y.W.), CPRIT (RP180047, Y.W.), DOD (W81XWH-18-1-0014, Y.W.), The Welch Foundation (I-1751, Y.W.) and UTSW Endowed Scholar Startup Fund (Y.W.). Y. Wan is Lawrence Raisz Professor in Bone Cell Metabolism and a Virginia Murchison Linthicum Scholar in Medical Research.

Conflicts of Interest: The authors declare no conflict of interest.

\section{Abbreviations}

LPS, lipopolysaccharide; IFN $\gamma$, Interferon gamma; TLR, Toll-like receptor; ETC, electron transport chain; FET, forward electron transport; RET, reverse electron transport; OXPHOS, oxidative phosphorylation; ROS, reactive oxygen species; CI, mitochondrial Complex I; CII, mitochondrial Complex II; CIII, mitochondrial Complex III; $\mathrm{m} \Phi$, macrophages; DCs, dendritic cells; BMDMs, bone marrow-derived macrophages; hMDMs, human monocyte-derived macrophages; PBMCs, peripheral blood mononuclear cells; BMDCs, bone marrow-derived dendritic cells; n.c. no change; HIF1 $\alpha$, Hypoxia-inducible factor- $1 \alpha$; mTOR, mammalian target of rapamycin; AMPK, AMP-activated protein kinase; ATP, adenosine triphosphate; $\mathrm{NADH}$, nicotinamide adenine dinucleotide; $\mathrm{FADH}_{2}$, flavin adenine dinucleotide reduced; TCA cycle, tricarboxylic acid cycle; ECAR, extracellular acidification rate; OCR, oxygen consumption rate; SRC, spare respiratory capacity; GPS, Glycerol 3-phosphate shuttle; GDP2, mitochondrial glycerol 3-phosphate dehydrogenase; iNOS, inducible nitric oxide synthase; NO, nitric oxide; FAS, fatty acid synthesis; FAO, fatty acid oxidation; CPT-1, Carnitine Palmitoyltransferase 1; MDSCs, myeloid-derived

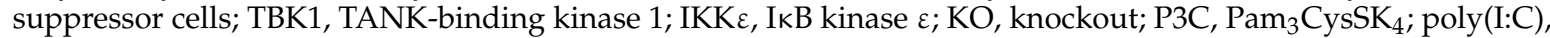
polyinosinic:polycytidylic acid; R848, Resiquimod; CpG, CpG oligodeoxynucleotides; NAC, N-acetyl cysteine; NLRP3, NACHT, LRR and PYD domains-containing protein 3; 3-MA, 3-methyladenine; $\alpha$ KG, $\alpha$-ketoglutarate; ACLY, ATP-citrate lyase; SDH, succinate dehydrogenase; NRF2, Nuclear factor erythroid 2-related factor 2; ATF3, Activating transcription factor 3; Q, ubiquinone; WT, wild-type; ECSIT, evolutionarily conserved signaling intermediate in Toll pathways; TRAF6, tumour necrosis factor receptor-associated factor 6; Myx, Myxothiazol; TAK1, TGF-beta-activated kinase 1; SREBP1c, sterol regulatory element-binding transcription factor 1c; GLUD2, Glutamate dehydrogenase 2; 2-DG, 2-deoxyglucose; IRF4, Interferon Regulatory Factor 4; IDH, isocitrate dehydrogenase; Drp1, dynamin-related protein 1; ANT, adenine nucleotide translocase; $\alpha-\mathrm{KGDH}, \alpha$-ketoglutarate dehydrogenase; AASS, aspartate-argininosuccinate shunt; $\Delta \Psi$, membrane potential; ML1-M, ML-1-derived monocytes/macrophages; LDCL, Lucigenin-derived chemiluminescence; $\mathrm{mROS}$, mitochondrial-derived reactive oxygen species; CIC, the citrate carrier; Cyt C, cytochrome c; Cryo-EM, cryogenic electron microscopy. 


\section{References}

1. Villavicencio, M.; Guzman Barron, E.S. Pathways of glucose metabolism in lymphatic cells of rabbit's appendix and Gardners's mouse lymphosarcoma. Arch. Biochem. Biophys. 1957, 67, 121-137. [CrossRef]

2. Oren, R.; Farnham, A.E.; Saito, K.; Milofsky, E.; Karnovsky, M.L. Metabolic patterns in three types of phagocytizing cells. J. Cell Biol. 1963, 17, 487-501. [CrossRef] [PubMed]

3. O'Neill, L.A.; Kishton, R.J.; Rathmell, J. A guide to immunometabolism for immunologists. Nat. Rev. Immunol. 2016, 16, 553-565. [CrossRef] [PubMed]

4. Buck, M.D.; O'Sullivan, D.; Pearce, E.L. T cell metabolism drives immunity. J. Exp. Med. 2015, 212, $1345-1360$. [CrossRef] [PubMed]

5. Iwasaki, H.; Akashi, K. Myeloid lineage commitment from the hematopoietic stem cell. Immunity 2007, 26, 726-740. [CrossRef]

6. Forman, H.J.; Torres, M. Reactive oxygen species and cell signaling: Respiratory burst in macrophage signaling. Am. J. Respir. Crit. Care Med. 2002, 166, S4-S8. [CrossRef]

7. Youle, R.J.; van der Bliek, A.M. Mitochondrial fission, fusion, and stress. Science 2012, 337, $1062-1065$. [CrossRef]

8. Lanca, T.; Silva-Santos, B. The split nature of tumor-infiltrating leukocytes: Implications for cancer surveillance and immunotherapy. Oncoimmunology 2012, 1, 717-725. [CrossRef]

9. Covarrubias, A.J.; Aksoylar, H.I.; Horng, T. Control of macrophage metabolism and activation by mTOR and Akt signaling. Semin. Immunol. 2015, 27, 286-296. [CrossRef]

10. O'Neill, L.A.; Hardie, D.G. Metabolism of inflammation limited by AMPK and pseudo-starvation. Nature 2013, 493, 346-355. [CrossRef]

11. Haschemi, A.; Kosma, P.; Gille, L.; Evans, C.R.; Burant, C.F.; Starkl, P.; Knapp, B.; Haas, R.; Schmid, J.A.; Jandl, C.; et al. The sedoheptulose kinase CARKL directs macrophage polarization through control of glucose metabolism. Cell Metab. 2012, 15, 813-826. [CrossRef] [PubMed]

12. Tannahill, G.M.; Curtis, A.M.; Adamik, J.; Palsson-McDermott, E.M.; McGettrick, A.F.; Goel, G.; Frezza, C.; Bernard, N.J.; Kelly, B.; Foley, N.H.; et al. Succinate is an inflammatory signal that induces IL-1beta through HIF-1alpha. Nature 2013, 496, 238-242. [CrossRef] [PubMed]

13. Langston, P.K.; Nambu, A.; Jung, J.; Shibata, M.; Aksoylar, H.I.; Lei, J.; Xu, P.; Doan, M.T.; Jiang, H.; MacArthur, M.R.; et al. Glycerol phosphate shuttle enzyme GPD2 regulates macrophage inflammatory responses. Nat. Immunol. 2019, 20, 1186-1195. [CrossRef] [PubMed]

14. Cameron, A.M.; Castoldi, A.; Sanin, D.E.; Flachsmann, L.J.; Field, C.S.; Puleston, D.J.; Kyle, R.L.; Patterson, A.E.; Hassler, F.; Buescher, J.M.; et al. Inflammatory macrophage dependence on NAD(+) salvage is a consequence of reactive oxygen species-mediated DNA damage. Nat. Immunol. 2019, 20, 420-432. [CrossRef] [PubMed]

15. Baseler, W.A.; Davies, L.C.; Quigley, L.; Ridnour, L.A.; Weiss, J.M.; Hussain, S.P.; Wink, D.A.; McVicar, D.W. Autocrine IL-10 functions as a rheostat for M1 macrophage glycolytic commitment by tuning nitric oxide production. Redox Biol. 2016, 10, 12-23. [CrossRef]

16. Wang, F.; Zhang, S.; Vuckovic, I.; Jeon, R.; Lerman, A.; Folmes, C.D.; Dzeja, P.P.; Herrmann, J. Glycolytic stimulation is not a requirement for $\mathrm{m} 2$ macrophage differentiation. Cell Metab. 2018, 28, 463-475. [CrossRef]

17. Rodriguez-Prados, J.C.; Traves, P.G.; Cuenca, J.; Rico, D.; Aragones, J.; Martin-Sanz, P.; Cascante, M.; Bosca, L. Substrate fate in activated macrophages: A comparison between innate, classic, and alternative activation. J. Immunol. 2010, 185, 605-614. [CrossRef]

18. Lachmandas, E.; Boutens, L.; Ratter, J.M.; Hijmans, A.; Hooiveld, G.J.; Joosten, L.A.; Rodenburg, R.J.; Fransen, J.A.; Houtkooper, R.H.; van Crevel, R.; et al. Microbial stimulation of different Toll-like receptor signalling pathways induces diverse metabolic programmes in human monocytes. Nat. Microbiol. 2016, 2, 16246. [CrossRef]

19. Raulien, N.; Friedrich, K.; Strobel, S.; Rubner, S.; Baumann, S.; von Bergen, M.; Korner, A.; Krueger, M.; Rossol, M.; Wagner, U. Fatty acid oxidation compensates for lipopolysaccharide-induced warburg effect in glucose-deprived monocytes. Front. Immunol. 2017, 8, 609. [CrossRef]

20. Everts, B.; Amiel, E.; van der Windt, G.J.; Freitas, T.C.; Chott, R.; Yarasheski, K.E.; Pearce, E.L.; Pearce, E.J. Commitment to glycolysis sustains survival of NO-producing inflammatory dendritic cells. Blood 2012, 120, 1422-1431. [CrossRef] 
21. Everts, B.; Amiel, E.; Huang, S.C.; Smith, A.M.; Chang, C.H.; Lam, W.Y.; Redmann, V.; Freitas, T.C.; Blagih, J.; van der Windt, G.J.; et al. TLR-driven early glycolytic reprogramming via the kinases TBK1-IKKvarepsilon supports the anabolic demands of dendritic cell activation. Nat. Immunol. 2014, 15, 323-332. [CrossRef] [PubMed]

22. Palsson-McDermott, E.M.; Curtis, A.M.; Goel, G.; Lauterbach, M.A.; Sheedy, F.J.; Gleeson, L.E.; van den Bosch, M.W.; Quinn, S.R.; Domingo-Fernandez, R.; Johnston, D.G.; et al. Pyruvate kinase M2 regulates Hif-1alpha activity and IL-1beta induction and is a critical determinant of the warburg effect in LPS-activated macrophages. Cell Metab. 2015, 21, 65-80. [CrossRef] [PubMed]

23. Liu, L.; Lu, Y.; Martinez, J.; Bi, Y.; Lian, G.; Wang, T.; Milasta, S.; Wang, J.; Yang, M.; Liu, G.; et al. Proinflammatory signal suppresses proliferation and shifts macrophage metabolism from Myc-dependent to HIF1alpha-dependent. Proc. Natl. Acad. Sci. USA 2016, 113, 1564-1569. [CrossRef] [PubMed]

24. Mills, E.L.; Kelly, B.; Logan, A.; Costa, A.S.H.; Varma, M.; Bryant, C.E.; Tourlomousis, P.; Dabritz, J.H.M.; Gottlieb, E.; Latorre, I.; et al. Succinate dehydrogenase supports metabolic repurposing of mitochondria to drive inflammatory macrophages. Cell 2016, 167, 457-470. [CrossRef]

25. Nemeth, B.; Doczi, J.; Csete, D.; Kacso, G.; Ravasz, D.; Adams, D.; Kiss, G.; Nagy, A.M.; Horvath, G.; Tretter, L.; et al. Abolition of mitochondrial substrate-level phosphorylation by itaconic acid produced by LPS-induced Irg1 expression in cells of murine macrophage lineage. FASEB J. Off. Publ. Fed. Am. Soc. Exp. Biol. 2016, 30, 286-300. [CrossRef]

26. Ip, W.K.E.; Hoshi, N.; Shouval, D.S.; Snapper, S.; Medzhitov, R. Anti-inflammatory effect of IL-10 mediated by metabolic reprogramming of macrophages. Science 2017, 356, 513-519. [CrossRef]

27. Vijayan, V.; Pradhan, P.; Braud, L.; Fuchs, H.R.; Gueler, F.; Motterlini, R.; Foresti, R.; Immenschuh, S. Human and murine macrophages exhibit differential metabolic responses to lipopolysaccharide-A divergent role for glycolysis. Redox Biol. 2019, 22, 101147. [CrossRef]

28. Cheng, S.C.; Quintin, J.; Cramer, R.A.; Shepardson, K.M.; Saeed, S.; Kumar, V.; Giamarellos-Bourboulis, E.J.; Martens, J.H.; Rao, N.A.; Aghajanirefah, A.; et al. mTOR-and HIF-1alpha-mediated aerobic glycolysis as metabolic basis for trained immunity. Science 2014, 345, 1250684. [CrossRef]

29. Cheng, S.C.; Scicluna, B.P.; Arts, R.J.; Gresnigt, M.S.; Lachmandas, E.; Giamarellos-Bourboulis, E.J.; Kox, M.; Manjeri, G.R.; Wagenaars, J.A.; Cremer, O.L.; et al. Broad defects in the energy metabolism of leukocytes underlie immunoparalysis in sepsis. Nat. Immunol. 2016, 17, 406-413. [CrossRef]

30. Scrima, R.; Menga, M.; Pacelli, C.; Agriesti, F.; Cela, O.; Piccoli, C.; Cotoia, A.; De Gregorio, A.; Gefter, J.V.; Cinnella, G.; et al. Para-hydroxyphenylpyruvate inhibits the pro-inflammatory stimulation of macrophage preventing LPS-mediated nitro-oxidative unbalance and immunometabolic shift. PLoS ONE 2017, 12, e0188683. [CrossRef]

31. Li, Y.; Jia, A.; Wang, Y.; Dong, L.; Wang, Y.; He, Y.; Wang, S.; Cao, Y.; Yang, H.; Bi, Y.; et al. Immune effects of glycolysis or oxidative phosphorylation metabolic pathway in protecting against bacterial infection. J. Cell. Physiol. 2019, 234, 20298-20309. [CrossRef] [PubMed]

32. Krawczyk, C.M.; Holowka, T.; Sun, J.; Blagih, J.; Amiel, E.; DeBerardinis, R.J.; Cross, J.R.; Jung, E.; Thompson, C.B.; Jones, R.G.; et al. Toll-like receptor-induced changes in glycolytic metabolism regulate dendritic cell activation. Blood 2010, 115, 4742-4749. [CrossRef] [PubMed]

33. Amiel, E.; Everts, B.; Fritz, D.; Beauchamp, S.; Ge, B.; Pearce, E.L.; Pearce, E.J. Mechanistic target of rapamycin inhibition extends cellular lifespan in dendritic cells by preserving mitochondrial function. J. Immunol. 2014, 193, 2821-2830. [CrossRef] [PubMed]

34. Hargrave, K.E.; Woods, S.; Millington, O.; Chalmers, S.; Westrop, G.D.; Roberts, C.W. Multi-omics studies demonstrate toxoplasma gondii-induced metabolic reprogramming of murine dendritic cells. Front. Cell. Infect. Microbiol. 2019, 9, 309. [CrossRef] [PubMed]

35. Nair, S.; Sobotka, K.S.; Joshi, P.; Gressens, P.; Fleiss, B.; Thornton, C.; Mallard, C.; Hagberg, H. Lipopolysaccharide-induced alteration of mitochondrial morphology induces a metabolic shift in microglia modulating the inflammatory response in vitro and in vivo. Glia 2019, 67, 1047-1061. [CrossRef] [PubMed]

36. Saeed, S.; Quintin, J.; Kerstens, H.H.; Rao, N.A.; Aghajanirefah, A.; Matarese, F.; Cheng, S.C.; Ratter, J.; Berentsen, K.; van der Ent, M.A.; et al. Epigenetic programming of monocyte-to-macrophage differentiation and trained innate immunity. Science 2014, 345, 1251086. [CrossRef] [PubMed]

37. Seeley, J.J.; Ghosh, S. Molecular mechanisms of innate memory and tolerance to LPS. J. Leukoc. Biol. 2017, 101, 107-119. [CrossRef] 
38. Vats, D.; Mukundan, L.; Odegaard, J.I.; Zhang, L.; Smith, K.L.; Morel, C.R.; Wagner, R.A.; Greaves, D.R.; Murray, P.J.; Chawla, A. Oxidative metabolism and PGC-1beta attenuate macrophage-mediated inflammation. Cell Metab. 2006, 4, 13-24. [CrossRef]

39. Covarrubias, A.J.; Aksoylar, H.I.; Yu, J.; Snyder, N.W.; Worth, A.J.; Iyer, S.S.; Wang, J.; Ben-Sahra, I.; Byles, V.; Polynne-Stapornkul, T.; et al. Akt-mTORC1 signaling regulates Acly to integrate metabolic input to control of macrophage activation. eLife 2016, 5, e11612. [CrossRef]

40. Huang, S.C.; Smith, A.M.; Everts, B.; Colonna, M.; Pearce, E.L.; Schilling, J.D.; Pearce, E.J. Metabolic reprogramming mediated by the mTORC2-IRF4 signaling axis is essential for macrophage alternative activation. Immunity 2016, 45, 817-830. [CrossRef]

41. Park, J.; Choi, H.; Min, J.S.; Park, S.J.; Kim, J.H.; Park, H.J.; Kim, B.; Chae, J.I.; Yim, M.; Lee, D.S. Mitochondrial dynamics modulate the expression of pro-inflammatory mediators in microglial cells. J. Neurochem. 2013, 127, 221-232. [CrossRef] [PubMed]

42. Katoh, M.; Wu, B.; Nguyen, H.B.; Thai, T.Q.; Yamasaki, R.; Lu, H.; Rietsch, A.M.; Zorlu, M.M.; Shinozaki, Y.; Saitoh, Y.; et al. Polymorphic regulation of mitochondrial fission and fusion modifies phenotypes of microglia in neuroinflammation. Sci. Rep. 2017, 7, 4942. [CrossRef] [PubMed]

43. Esteban-Martinez, L.; Sierra-Filardi, E.; McGreal, R.S.; Salazar-Roa, M.; Marino, G.; Seco, E.; Durand, S.; Enot, D.; Grana, O.; Malumbres, M.; et al. Programmed mitophagy is essential for the glycolytic switch during cell differentiation. EMBO J. 2017, 36, 1688-1706. [CrossRef] [PubMed]

44. Gao, Z.; Li, Y.; Wang, F.; Huang, T.; Fan, K.; Zhang, Y.; Zhong, J.; Cao, Q.; Chao, T.; Jia, J.; et al. Mitochondrial dynamics controls anti-tumour innate immunity by regulating CHIP-IRF1 axis stability. Nat. Commun. 2017, 8, 1805. [CrossRef] [PubMed]

45. Cassidy-Stone, A.; Chipuk, J.E.; Ingerman, E.; Song, C.; Yoo, C.; Kuwana, T.; Kurth, M.J.; Shaw, J.T.; Hinshaw, J.E.; Green, D.R.; et al. Chemical inhibition of the mitochondrial division dynamin reveals its role in Bax/Bak-dependent mitochondrial outer membrane permeabilization. Dev. Cell 2008, 14, 193-204. [CrossRef]

46. Wang, Y.; Subramanian, M.; Yurdagul, A., Jr.; Barbosa-Lorenzi, V.C.; Cai, B.; de Juan-Sanz, J.; Ryan, T.A.; Nomura, M.; Maxfield, F.R.; Tabas, I. Mitochondrial fission promotes the continued clearance of apoptotic cells by macrophages. Cell 2017, 171, 331-345. [CrossRef]

47. Bordt, E.A.; Clerc, P.; Roelofs, B.A.; Saladino, A.J.; Tretter, L.; Adam-Vizi, V.; Cherok, E.; Khalil, A.; Yadava, N.; Ge, S.X.; et al. The putative Drp1 inhibitor mdivi-1 is a reversible mitochondrial complex I inhibitor that modulates reactive oxygen species. Dev. Cell 2017, 40, 583-594. [CrossRef]

48. Twig, G.; Shirihai, O.S. The interplay between mitochondrial dynamics and mitophagy. Antioxid. Redox Signal. 2011, 14, 1939-1951. [CrossRef]

49. Zhou, R.; Yazdi, A.S.; Menu, P.; Tschopp, J. A role for mitochondria in NLRP3 inflammasome activation. Nature 2011, 469, 221-225. [CrossRef]

50. Zhong, Z.; Umemura, A.; Sanchez-Lopez, E.; Liang, S.; Shalapour, S.; Wong, J.; He, F.; Boassa, D.; Perkins, G.; Ali, S.R.; et al. NF-kappaB restricts inflammasome activation via elimination of damaged mitochondria. Cell 2016, 164, 896-910. [CrossRef]

51. Jha, A.K.; Huang, S.C.; Sergushichev, A.; Lampropoulou, V.; Ivanova, Y.; Loginicheva, E.; Chmielewski, K.; Stewart, K.M.; Ashall, J.; Everts, B.; et al. Network integration of parallel metabolic and transcriptional data reveals metabolic modules that regulate macrophage polarization. Immunity 2015, 42, 419-430. [CrossRef] [PubMed]

52. Infantino, V.; Convertini, P.; Cucci, L.; Panaro, M.A.; Di Noia, M.A.; Calvello, R.; Palmieri, F.; Iacobazzi, V. The mitochondrial citrate carrier: A new player in inflammation. Biochem. J. 2011, 438, 433-436. [CrossRef] [PubMed]

53. Wellen, K.E.; Hatzivassiliou, G.; Sachdeva, U.M.; Bui, T.V.; Cross, J.R.; Thompson, C.B. ATP-citrate lyase links cellular metabolism to histone acetylation. Science 2009, 324, 1076-1080. [CrossRef] [PubMed]

54. Strelko, C.L.; Lu, W.; Dufort, F.J.; Seyfried, T.N.; Chiles, T.C.; Rabinowitz, J.D.; Roberts, M.F. Itaconic acid is a mammalian metabolite induced during macrophage activation. J. Am. Chem. Soc. 2011, 133, 16386-16389. [CrossRef]

55. Michelucci, A.; Cordes, T.; Ghelfi, J.; Pailot, A.; Reiling, N.; Goldmann, O.; Binz, T.; Wegner, A.; Tallam, A.; Rausell, A.; et al. Immune-responsive gene 1 protein links metabolism to immunity by catalyzing itaconic acid production. Proc. Natl. Acad. Sci. USA 2013, 110, 7820-7825. [CrossRef] 
56. Cordes, T.; Wallace, M.; Michelucci, A.; Divakaruni, A.S.; Sapcariu, S.C.; Sousa, C.; Koseki, H.; Cabrales, P.; Murphy, A.N.; Hiller, K.; et al. Immunoresponsive gene 1 and itaconate inhibit succinate dehydrogenase to modulate intracellular succinate levels. J. Biol. Chem. 2016, 291, 14274-14284. [CrossRef]

57. Lampropoulou, V.; Sergushichev, A.; Bambouskova, M.; Nair, S.; Vincent, E.E.; Loginicheva, E.; Cervantes-Barragan, L.; Ma, X.; Huang, S.C.; Griss, T.; et al. Itaconate Links inhibition of succinate dehydrogenase with macrophage metabolic remodeling and regulation of inflammation. Cell Metab. 2016, 24, 158-166. [CrossRef]

58. Mills, E.L.; Ryan, D.G.; Prag, H.A.; Dikovskaya, D.; Menon, D.; Zaslona, Z.; Jedrychowski, M.P.; Costa, A.S.H.; Higgins, M.; Hams, E.; et al. Itaconate is an anti-inflammatory metabolite that activates Nrf2 via alkylation of KEAP1. Nature 2018, 556, 113-117. [CrossRef]

59. Bambouskova, M.; Gorvel, L.; Lampropoulou, V.; Sergushichev, A.; Loginicheva, E.; Johnson, K.; Korenfeld, D.; Mathyer, M.E.; Kim, H.; Huang, L.H.; et al. Electrophilic properties of itaconate and derivatives regulate the IkappaBzeta-ATF3 inflammatory axis. Nature 2018, 556, 501-504. [CrossRef]

60. Dominguez-Andres, J.; Novakovic, B.; Li, Y.; Scicluna, B.P.; Gresnigt, M.S.; Arts, R.J.W.; Oosting, M.; Moorlag, S.; Groh, L.A.; Zwaag, J.; et al. The itaconate pathway is a central regulatory node linking innate immune tolerance and trained immunity. Cell Metab. 2019, 29, 211-220. [CrossRef]

61. Kelly, B.; O'Neill, L.A. Metabolic reprogramming in macrophages and dendritic cells in innate immunity. Cell Res. 2015, 25, 771-784. [CrossRef]

62. Wallace, C.; Keast, D. Glutamine and macrophage function. Metab. Clin. Exp. 1992, 41, 1016-1020. [CrossRef]

63. Liu, P.S.; Wang, H.; Li, X.; Chao, T.; Teav, T.; Christen, S.; Di Conza, G.; Cheng, W.C.; Chou, C.H.; Vavakova, M.; et al. alpha-ketoglutarate orchestrates macrophage activation through metabolic and epigenetic reprogramming. Nat. Immunol. 2017, 18, 985-994. [CrossRef]

64. Scialo, F.; Fernandez-Ayala, D.J.; Sanz, A. Role of Mitochondrial Reverse Electron Transport in ROS Signaling: Potential Roles in Health and Disease. Front. Physiol. 2017, 8, 428. [CrossRef]

65. Robb, E.L.; Hall, A.R.; Prime, T.A.; Eaton, S.; Szibor, M.; Viscomi, C.; James, A.M.; Murphy, M.P. Control of mitochondrial superoxide production by reverse electron transport at complex I. J. Biol. Chem. 2018, 293, 9869-9879. [CrossRef]

66. Koopman, W.J.; Verkaart, S.; Visch, H.J.; van der Westhuizen, F.H.; Murphy, M.P.; van den Heuvel, L.W.; Smeitink, J.A.; Willems, P.H. Inhibition of complex I of the electron transport chain causes $\mathrm{O}^{-}{ }^{-}$. -mediated mitochondrial outgrowth. Am. J. Physiol. Cell Physiol. 2005, 288, C1440-C1450. [CrossRef]

67. Votyakova, T.V.; Reynolds, I.J. DeltaPsi(m)-Dependent and -independent production of reactive oxygen species by rat brain mitochondria. J. Neurochem. 2001, 79, 266-277. [CrossRef]

68. Li, Y.; Trush, M.A. Diphenyleneiodonium, an NAD(P)H oxidase inhibitor, also potently inhibits mitochondrial reactive oxygen species production. Biochem. Biophys. Res. Commun. 1998, 253, 295-299. [CrossRef]

69. Garaude, J.; Acin-Perez, R.; Martinez-Cano, S.; Enamorado, M.; Ugolini, M.; Nistal-Villan, E.; Hervas-Stubbs, S.; Pelegrin, P.; Sander, L.E.; Enriquez, J.A.; et al. Mitochondrial respiratory-chain adaptations in macrophages contribute to antibacterial host defense. Nat. Immunol. 2016, 17, 1037-1045. [CrossRef]

70. Rembish, S.J.; Trush, M.A. Further evidence that lucigenin-derived chemiluminescence monitors mitochondrial superoxide generation in rat alveolar macrophages. Free Radic. Biol. Med. 1994, 17, 117-126. [CrossRef]

71. Li, N.; Ragheb, K.; Lawler, G.; Sturgis, J.; Rajwa, B.; Melendez, J.A.; Robinson, J.P. Mitochondrial complex I inhibitor rotenone induces apoptosis through enhancing mitochondrial reactive oxygen species production. J. Biol. Chem. 2003, 278, 8516-8525. [CrossRef]

72. Giardina, T.M.; Steer, J.H.; Lo, S.Z.; Joyce, D.A. Uncoupling protein-2 accumulates rapidly in the inner mitochondrial membrane during mitochondrial reactive oxygen stress in macrophages. Biochim. Biophys. Acta 2008, 1777, 118-129. [CrossRef]

73. Nakahira, K.; Haspel, J.A.; Rathinam, V.A.; Lee, S.J.; Dolinay, T.; Lam, H.C.; Englert, J.A.; Rabinovitch, M.; Cernadas, M.; Kim, H.P.; et al. Autophagy proteins regulate innate immune responses by inhibiting the release of mitochondrial DNA mediated by the NALP3 inflammasome. Nat. Immunol. 2011, 12, 222-230. [CrossRef]

74. West, A.P.; Brodsky, I.E.; Rahner, C.; Woo, D.K.; Erdjument-Bromage, H.; Tempst, P.; Walsh, M.C.; Choi, Y.; Shadel, G.S.; Ghosh, S. TLR signalling augments macrophage bactericidal activity through mitochondrial ROS. Nature 2011, 472, 476-480. [CrossRef] 
75. Zhou, H.; Zhang, F.; Chen, S.H.; Zhang, D.; Wilson, B.; Hong, J.S.; Gao, H.M. Rotenone activates phagocyte NADPH oxidase by binding to its membrane subunit gp91phox. Free Radic. Biol. Med. 2012, 52, 303-313. [CrossRef]

76. Yuan, Y.H.; Sun, J.D.; Wu, M.M.; Hu, J.F.; Peng, S.Y.; Chen, N.H. Rotenone could activate microglia through NFkappaB associated pathway. Neurochem. Res. 2013, 38, 1553-1560. [CrossRef]

77. Gao, F.; Chen, D.; Hu, Q.; Wang, G. Rotenone directly induces BV2 cell activation via the p38 MAPK pathway. PLoS ONE 2013, 8, e72046. [CrossRef]

78. Du, C.; Jin, M.; Hong, Y.; Li, Q.; Wang, X.H.; Xu, J.M.; Wang, F.; Zhang, Y.; Jia, J.; Liu, C.F.; et al. Downregulation of cystathionine beta-synthase/hydrogen sulfide contributes to rotenone-induced microglia polarization toward M1 type. Biochem. Biophys. Res. Commun. 2014, 451, 239-245. [CrossRef]

79. Kelly, B.; Tannahill, G.M.; Murphy, M.P.; O'Neill, L.A. Metformin inhibits the production of reactive oxygen species from NADH:Ubiquinone oxidoreductase to Limit Induction of Interleukin-1beta (IL-1beta) and boosts Interleukin-10 (IL-10) in Lipopolysaccharide (LPS)-activated macrophages. J. Biol. Chem. 2015, 290, 20348-20359. [CrossRef]

80. Won, J.H.; Park, S.; Hong, S.; Son, S.; Yu, J.W. Rotenone-induced impairment of mitochondrial electron transport chain confers a selective priming signal for NLRP3 inflammasome activation. J. Biol. Chem. 2015, 290, 27425-27437. [CrossRef]

81. Li, Y.; Zhu, H.; Kuppusamy, P.; Zweier, J.L.; Trush, M.A. Mitochondrial electron transport chain-derived superoxide exits macrophages: Implications for mononuclear cell-mediated pathophysiological processes. React. Oxyg. Species 2016, 1, 81-98. [CrossRef]

82. Liu, X.; Zhang, X.; Ding, Y.; Zhou, W.; Tao, L.; Lu, P.; Wang, Y.; Hu, R. Nuclear factor E2-related factor-2 negatively regulates NLRP3 inflammasome activity by inhibiting reactive oxygen species-induced NLRP3 priming. Antioxid. Redox Signal. 2017, 26, 28-43. [CrossRef]

83. Chandel, N.S.; Trzyna, W.C.; McClintock, D.S.; Schumacker, P.T. Role of oxidants in NF-kappa B activation and TNF-alpha gene transcription induced by hypoxia and endotoxin. J. Immunol. 2000, 165, 1013-1021. [CrossRef]

84. Woo, C.H.; Lim, J.H.; Kim, J.H. Lipopolysaccharide induces matrix metalloproteinase-9 expression via a mitochondrial reactive oxygen species-p38 kinase-activator protein-1 pathway in Raw 264.7 cells. J. Immunol. 2004, 173, 6973-6980. [CrossRef]

85. Wu, X.; Gao, H.; Hou, Y.; Yu, J.; Sun, W.; Wang, Y.; Chen, X.; Feng, Y.; Xu, Q.M.; Chen, X. Dihydronortanshinone, a natural product, alleviates LPS-induced inflammatory response through NF-kappaB, mitochondrial ROS, and MAPK pathways. Toxicol. Appl. Pharmacol. 2018, 355, 1-8. [CrossRef]

86. Fassone, E.; Rahman, S. Complex I deficiency: Clinical features, biochemistry and molecular genetics. J. Med. Genet. 2012, 49, 578-590. [CrossRef]

87. Calvaruso, M.A.; Willems, P.; van den Brand, M.; Valsecchi, F.; Kruse, S.; Palmiter, R.; Smeitink, J.; Nijtmans, L. Mitochondrial complex III stabilizes complex I in the absence of NDUFS4 to provide partial activity. Hum. Mol. Genet. 2012, 21, 115-120. [CrossRef]

88. Leong, D.W.; Komen, J.C.; Hewitt, C.A.; Arnaud, E.; McKenzie, M.; Phipson, B.; Bahlo, M.; Laskowski, A.; Kinkel, S.A.; Davey, G.M.; et al. Proteomic and metabolomic analyses of mitochondrial complex I-deficient mouse model generated by spontaneous B2 short interspersed nuclear element (SINE) insertion into NADH dehydrogenase (ubiquinone) Fe-S protein 4 (Ndufs4) gene. J. Biol. Chem. 2012, 287, 20652-20663. [CrossRef]

89. Kruse, S.E.; Watt, W.C.; Marcinek, D.J.; Kapur, R.P.; Schenkman, K.A.; Palmiter, R.D. Mice with mitochondrial complex I deficiency develop a fatal encephalomyopathy. Cell Metab. 2008, 7, 312-320. [CrossRef]

90. Wang, M.; Huang, Y.P.; Wu, H.; Song, K.; Wan, C.; Chi, A.N.; Xiao, Y.M.; Zhao, X.Y. Mitochondrial complex I deficiency leads to the retardation of early embryonic development in Ndufs4 knockout mice. PeerJ 2017, 5, e3339. [CrossRef]

91. Jin, Z.; Wei, W.; Yang, M.; Du, Y.; Wan, Y. Mitochondrial complex I activity suppresses inflammation and enhances bone resorption by shifting macrophage-osteoclast polarization. Cell Metab. 2014, 20, 483-498. [CrossRef] [PubMed]

92. Huang, S.; Rutkowsky, J.M.; Snodgrass, R.G.; Ono-Moore, K.D.; Schneider, D.A.; Newman, J.W.; Adams, S.H.; Hwang, D.H. Saturated fatty acids activate TLR-mediated proinflammatory signaling pathways. J. Lipid Res. 2012, 53, 2002-2013. [CrossRef] [PubMed] 
93. Vogel, R.O.; Janssen, R.J.; van den Brand, M.A.; Dieteren, C.E.; Verkaart, S.; Koopman, W.J.; Willems, P.H.; Pluk, W.; van den Heuvel, L.P.; Smeitink, J.A.; et al. Cytosolic signaling protein Ecsit also localizes to mitochondria where it interacts with chaperone NDUFAF1 and functions in complex I assembly. Genes Dev. 2007, 21, 615-624. [CrossRef] [PubMed]

94. Carneiro, F.R.G.; Lepelley, A.; Seeley, J.J.; Hayden, M.S.; Ghosh, S. An essential role for ECSIT in mitochondrial complex i assembly and mitophagy in macrophages. Cell Rep. 2018, 22, 2654-2666. [CrossRef]

95. Wi, S.M.; Moon, G.; Kim, J.; Kim, S.T.; Shim, J.H.; Chun, E.; Lee, K.Y. TAK1-ECSIT-TRAF6 complex plays a key role in the TLR4 signal to activate NF-kappaB. J. Biol. Chem. 2014, 289, 35205-35214. [CrossRef]

96. Bleier, L.; Drose, S. Superoxide generation by complex III: From mechanistic rationales to functional consequences. Biochim. Biophys. Acta 2013, 1827, 1320-1331. [CrossRef]

97. Zmijewski, J.W.; Lorne, E.; Banerjee, S.; Abraham, E. Participation of mitochondrial respiratory complex III in neutrophil activation and lung injury. Am. J. Physiol. Lung Cell. Mol. Physiol. 2009, 296, L624-L634. [CrossRef]

98. Feingold, K.R.; Shigenaga, J.K.; Kazemi, M.R.; McDonald, C.M.; Patzek, S.M.; Cross, A.S.; Moser, A.; Grunfeld, C. Mechanisms of triglyceride accumulation in activated macrophages. J. Leukoc. Biol. 2012, 92, 829-839. [CrossRef]

99. Posokhova, E.N.; Khoshchenko, O.M.; Chasovskikh, M.I.; Pivovarova, E.N.; Dushkin, M.I. Lipid synthesis in macrophages during inflammation in vivo: Effect of agonists of peroxisome proliferator activated receptors alpha and gamma and of retinoid X receptors. Biochem. Biokhimiia 2008, 73, 296-304. [CrossRef]

100. Ecker, J.; Liebisch, G.; Englmaier, M.; Grandl, M.; Robenek, H.; Schmitz, G. Induction of fatty acid synthesis is a key requirement for phagocytic differentiation of human monocytes. Proc. Natl. Acad. Sci. USA 2010, 107, 7817-7822. [CrossRef]

101. Carroll, R.G.; Zaslona, Z.; Galvan-Pena, S.; Koppe, E.L.; Sevin, D.C.; Angiari, S.; Triantafilou, M.; Triantafilou, K.; Modis, L.K.; O'Neill, L.A. An unexpected link between fatty acid synthase and cholesterol synthesis in proinflammatory macrophage activation. J. Biol. Chem. 2018, 293, 5509-5521. [CrossRef] [PubMed]

102. Divakaruni, A.S.; Hsieh, W.Y.; Minarrieta, L.; Duong, T.N.; Kim, K.K.O.; Desousa, B.R.; Andreyev, A.Y.; Bowman, C.E.; Caradonna, K.; Dranka, B.P.; et al. Etomoxir inhibits macrophage polarization by disrupting CoA homeostasis. Cell Metab. 2018, 28, 490-503. [CrossRef] [PubMed]

103. Huang, S.C.; Everts, B.; Ivanova, Y.; O'Sullivan, D.; Nascimento, M.; Smith, A.M.; Beatty, W.; Love-Gregory, L.; Lam, W.Y.; O'Neill, C.M.; et al. Cell-intrinsic lysosomal lipolysis is essential for alternative activation of macrophages. Nat. Immunol. 2014, 15, 846-855. [CrossRef] [PubMed]

104. Hossain, F.; Al-Khami, A.A.; Wyczechowska, D.; Hernandez, C.; Zheng, L.; Reiss, K.; Valle, L.D.; Trillo-Tinoco, J.; Maj, T.; Zou, W.; et al. Inhibition of fatty acid oxidation modulates immunosuppressive functions of myeloid-derived suppressor cells and enhances cancer therapies. Cancer Immunol. Res. 2015, 3, 1236-1247. [CrossRef]

105. Namgaladze, D.; Brune, B. Fatty acid oxidation is dispensable for human macrophage IL-4-induced polarization. Biochim. Biophys. Acta 2014, 1841, 1329-1335. [CrossRef]

106. Nomura, M.; Liu, J.; Rovira, I.I.; Gonzalez-Hurtado, E.; Lee, J.; Wolfgang, M.J.; Finkel, T. Fatty acid oxidation in macrophage polarization. Nat. Immunol. 2016, 17, 216-217. [CrossRef]

107. Koeken, V.; Lachmandas, E.; Riza, A.; Matzaraki, V.; Li, Y.; Kumar, V.; Oosting, M.; Joosten, L.A.B.; Netea, M.G.; van Crevel, R. Role of glutamine metabolism in host defense against mycobacterium tuberculosis infection. J. Infect. Dis. 2019, 219, 1662-1670. [CrossRef]

(C) 2019 by the authors. Licensee MDPI, Basel, Switzerland. This article is an open access article distributed under the terms and conditions of the Creative Commons Attribution (CC BY) license (http://creativecommons.org/licenses/by/4.0/). 